\title{
PARTIAL TRANSPLANTATION OF THE LEVATOR PALPEBRAE SUPERIORIS IN SUPERIOR RECTUS PALSY*
}

BY

\author{
H. B. STALLARD
}

London

THE following case report shows that a reasonable result, both functional and cosmetic, may be obtained by the transplantation of the central third of a normally acting levator palpebrae superioris into a completely paralysed superior rectus.

\section{Case Report}

J. W., aged 23, had paralysis of the left superior rectus muscle since birth. The left eye was deviated downwards and outwards (Fig. 1), there was complete absence

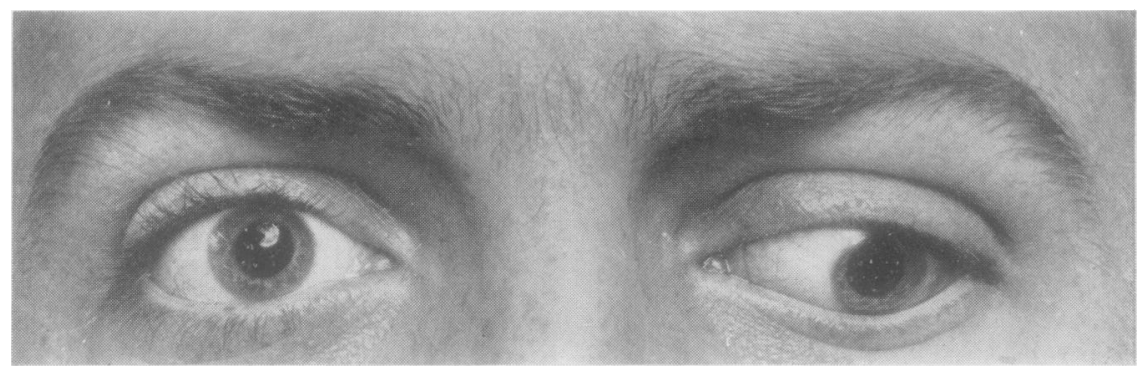

Fig. 1.-Photograph of deviation of left eye before operation.

of elevation, fixation was eccentric, and there were nystagmoid movements in this eye. There was slight ptosis, the left interpalpebral fissure being $9 \mathrm{~mm}$. at its highest point and the right $10 \mathrm{~mm}$. The action of the levator palpebrae superioris was good. There was marked secondary contracture of the inferior rectus muscle.

Operative intervention was carried out in two stages with a five-week interval between them.

(1) Recession of the inferior rectus $7 \mathrm{~mm}$., which was found to be in tight contracture. Recession of the external rectus to the equator, and resection of $5 \mathrm{~mm}$. of the internal rectus. Fig. 2 shows the result after this operation; the patient is looking up.

(2) Resection of $7 \mathrm{~mm}$. of the paralysed superior rectus and transplantation of the

* Received for publication July 26, 1951. 


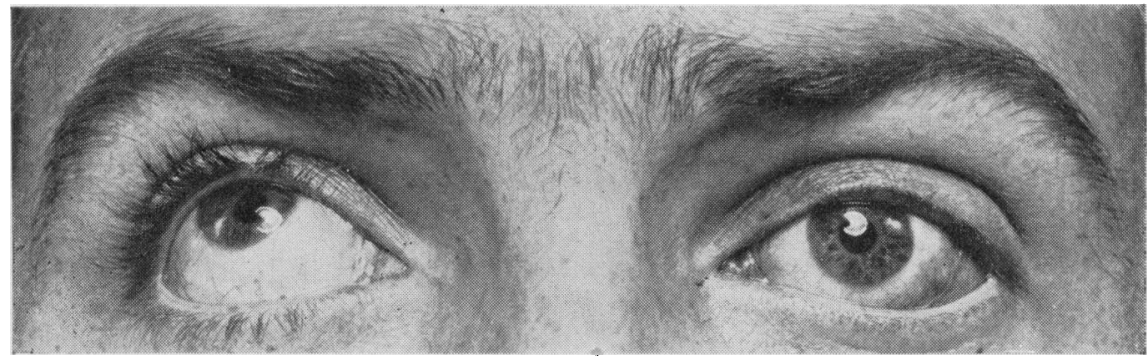

Fig. 2.-Photograph after first operation. Patient looking up.

central third of the levator palpebrae superioris cut at a site $1 \mathrm{~cm}$. posterior to the upper edge of the tarsal plate and secured with lateral whip stitches of white silk to the upper surface of the resected superior rectus muscle at its insertion. This procedure is illustrated in Fig. 3, which shows also the details of exposure of both the under surface of the levator palpebrae superioris and the superior rectus muscle through an incision in the conjunctiva of the upper fornix. The upper lid is everted over a 'cigarette' roll of gauze and is held thus by two traction sutures in the lid margin. These sutures are clamped to the head towel. The upper margin of the conjunctival incision is held

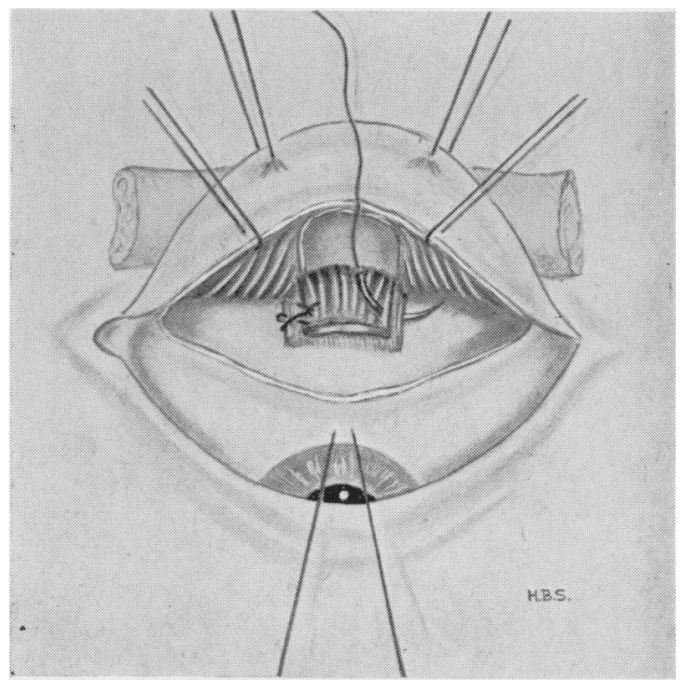

Fig. 3.-Diagram to show transplantation of middle third of levator palpebrae superioris into superior rectus muscle after its resection (second operation).

forwards and upwards by two traction sutures so as to facilitate and increase the exposure of the levator palpebrae superioris and the upper edge of the tarsal plate. A traction suture at 12 o'clock just above the limbus rotates the eye downwards.

To correct the small degree of original ptosis and any impairment of elevation of the lid caused by the transplantation of the central third of the levator, the medial and lateral thirds of this muscle were advanced on to the anterior surface of the tarsal plate. 


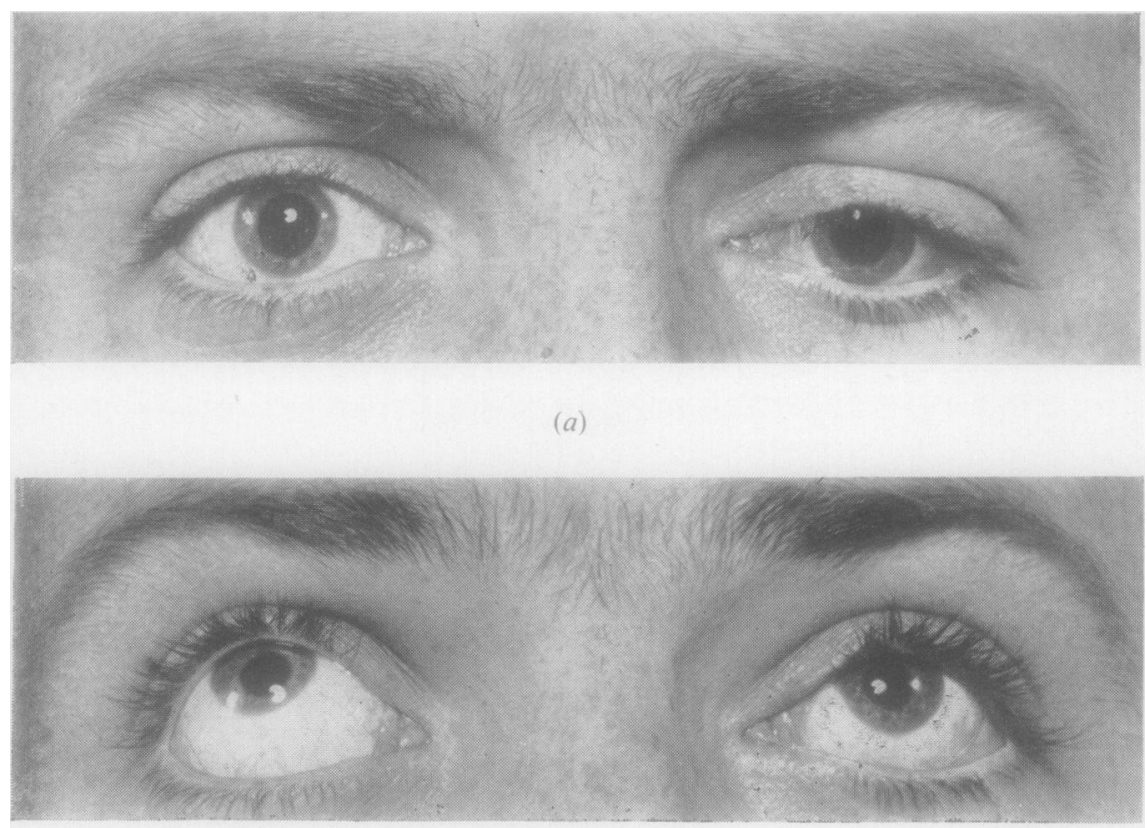

(b)

Fig. 4.-Photographs 6 months after second operation. (a) Looking to the front. (b) Looking up.

Fig. 4(a) and (b) shows the result 6 months after operation. The action of the left superior rectus, although not so good as the normal right side, is fair. Cosmetically, the improvement is appreciable.

I should like to thank Mr. P. G. Doyne for his kindness in sending the this patient. 